\title{
A CONSTRUÇÃO DEMOCRÁTICA DO DIREITO À ALIMENTAÇÃO ADEQUADA E A REGULAÇÃO DE ALIMENTOS
}

The democratic construction of the right to adequate nourishment and food regulation

${ }^{1}$ Universidade de Brasília. Brasília/DF, Brasil.

Correspondência: Eduardo Gonçalves Rocha. E-mail: eduardofdufg@yahoo.com.br.

Recebido em: 16/01/2016. 
Em 2006, foi promulgada a lei brasileira de segurança alimentar e nutricional - Lei n. 11.346/2006 ${ }^{1}$-, conhecida como Losan. Sem dúvidas, foi um marco e uma grande conquista no reconhecimento e na defesa do direito à alimentação no Brasil. É a primeira legislação pátria que enuncia a alimentação como um direito fundamental, trazendo já nos seus artigos $2^{\circ}$ e $3^{\circ}$ definições amplas, mas precisas, sobre o significado do direito à alimentação e da segurança alimentar e nutricional.

Mais do que simples conceitos, os artigos da Losan são parâmetros normativos assumidos pelo Estado brasileiro. Servem como diretrizes para a formulação de políticas públicas; limites para a ação do mercado; e referências para a atuação de cada cidadão e ator da sociedade civil na defesa por maior efetividade do direito à alimentação.

Direitos surgem como consequência de lutas por reconhecimento protagonizadas na esfera pública em determinado contexto histórico. A positivação é apenas uma parte desse processo, pois os direitos estão em permanente construção. Os artigos dessa seção podem ser interpretados sob esse ângulo, ou seja, como respostas férteis sobre o que significa ou deve significar a alimentação adequada, em um esforço acadêmico-social que tem como objetivo (re)dizê-la.

A Losan é uma legislação que ensina muito sobre o reconhecimento e sobre os desafios que se impõem aos direitos. Ela é o resultado e uma etapa de uma intensa mobilização social que dura, ao menos, 70 anos. Período, como muito bem demonstra Rosana Magalhães em "Regulação de alimentos no Brasil", em que ocorreram conquistas e retrocessos, em uma tensão constante entre sociedade civil, Estado e mercados.

Olhar para o passado pode exprimir um pouco a construção democrática do direito à alimentação e como ele permanece aberto a novas interpretações e reivindicações.

O Brasil descobriu a fome como um problema somente na década de 1940. Pode parecer absurdo aos olhos atuais, contudo foram necessárias as reflexões de Josué de Castro para que ela fosse discutida na esfera pública como consequência das desigualdades sociais, e não como consequência natural de fatores climáticos, geográficos e humanos. Josué de Castro demonstrou como amplos setores da população brasileira viviam em um estado permanente de fome crônica e aguda, resultante de relações sociais desiguais. Se há meios para livrar o faminto de seu mal, então a carência de comida e nutrientes não pode mais ser entendida como um problema natural, mas sim de justiça social. Na década de 1940, pôde-se compreender que a fome é injusta, sendo, portanto, dever do Estado brasileiro desenvolver políticas públicas para seu enfrentamento.

${ }^{1}$ BRASIL. Lei n. 11.346, de 15 de setembro de 2006. Cria o Sistema Nacional de Segurança Alimentar e Nutricional - SISAN com vistas em assegurar o direito humano à alimentação adequada e dá outras providências. Disponível em: <http://www.planalto.gov.br/ccivil_03/_ato2004-2006/2006/lei/I11346. htm>. Acesso em: 31 jan. 2017. 
A história não é um processo linear. A ditadura brasileira exilou Josué de Castro e, igualmente, silenciou todo o conjunto de reivindicações que ele sintetizava, além de desarticular programas e projetos já existentes - momento de enorme retrocesso democrático e na efetivação de direitos.

Foi com a redemocratização do país que o tema voltou a se apresentar com força na esfera pública. Mais uma vez, a sociedade civil foi a grande protagonista em dizer que passar fome era injusto, sendo um dever do Estado, do mercado e da própria sociedade combatê-la. Nesse contexto, os problemas sociais brasileiros começaram a ser debatidos com mais transparência e força, possibilitando uma maior tensão entre a sociedade civil e o Estado, tornando este mais permeável a novas demandas, e gerando acúmulos democráticos e a emergência de novos direitos.

Até a década de 1980, lutava-se pela superação da fome, não pela realização do direito à alimentação adequada e por um regime de segurança alimentar e nutricional. Essa não é apenas uma diferença semântica, mas sim a expressão dos limites reivindicatórios impostos por um determinado tempo. Há uma diferença qualitativa enorme entre enfrentar a fome e lutar pelo direito à alimentação. Este ainda não estava colocado de forma clara no horizonte de lutas e reivindicação da sociedade brasileira. Hoje em dia, a alimentação apresenta-se indissociável da dignidade humana e dos direitos fundamentais sociais e individuais presentes na Constituição de 1988 (CF/88), como muito bem apresentou Tarcisio Miguel Teixeira. Contudo, nem sempre foi assim.

Foi no intercurso da redemocratização e da consolidação da CF/88 que a fome começou a ser associada a uma questão de cidadania. A "Ação da Cidadania contra a Fome, a Miséria e pela Vida”, liderada pelo sociólogo Hebert de Souza, o Betinho, foi fundamental nesse sentido, mas não apenas. Na década de 1990, inúmeros processos sociais contribuíram para isso. O governo Collor, procurando angariar apoio diante de sua crise, ratificou em 1992 o Pacto Internacional de Direitos Econômicos, Sociais e Culturais ${ }^{2}$, que em seu artigo 11 assegura o direito à alimentação adequada. O governo Itamar Franco, pressionado pela sociedade civil, estabeleceu como objetivo de seu governo o enfrentamento do círculo vicioso entre fome, miséria e violência. Em 1993, foi criado o Conselho Nacional de Segurança Alimentar e Nutricional (Consea), tornando a segurança alimentar uma questão de governo ${ }^{3}$.

Com o fim da ditadura e a emergência de novos espaços democráticos, a sociedade civil brasileira acumulou demandas e avançou na reivindicação de novos direitos, o que permitiu uma transição processual entre o combate à fome e a luta pelo direito à alimentação. $\mathrm{O}$ amadurecimento democrático possibilitou

${ }^{2}$ BRASIL. Decreto n. 591, de 6 de julho de 1992. Atos Internacionais. Pacto Internacional sobre Direitos Econômicos, Sociais e Culturais. Promulgação. Disponível em: <http://www.planalto.gov.br/ccivil_03/ decreto/1990-1994/d0591.htm>. Acesso em: 31 jan. 2017.

${ }^{3}$ ROCHA, E. G. Direito à alimentação: teoria constitucional-democrática e políticas públicas. São Paulo: LTr, 2011. 
experiências e reivindicações que ocasionaram a emergência de um novo direito. O que antes era implausível, que não era compreendido em razão das limitações históricas, começou a tornar-se óbvio. Hoje, já se pode perguntar: como foi possível pensar em dignidade da pessoa humana sem associá-la ao direito à alimentação?

No final da década de 1990, em especial após a Cúpula Mundial de Alimentação de 1996, a alimentação passou a ser associada explicitamente a um direito. Falar em enfrentamento da fome tornou-se limitado, reducionista. Abria-se, assim, todo um campo de novas reflexões, reivindicações e lutas. Começava-se a se perguntar: se, afinal, o direito à alimentação não pode ser reduzido ao ato de comer, em que ele consiste?

A despeito de o Estado brasileiro reconhecer em documentos infralegais a existência do direito à alimentação, ainda não existia uma legislação clara que o reconhecesse e regulasse. Se parte da sociedade civil brasileira assumiu a luta pela alimentação como um direito já no final dos anos 1990, os anos 2000 foram marcados pelo aprendizado sobre o que ele significava, bem como pela luta por sua positivação.

Esse momento histórico é muito interessante, pois há uma crescente reivindicação pela positivação do direito à alimentação, mas, ao mesmo tempo, há um silêncio acadêmico enorme sobre o assunto. Um dado relevante, por exemplo, é que até 2006 existia apenas um livro que se dedicava explicitamente à matéria no Brasil, o do médico sanitarista Flávio Valente ${ }^{4}$. Entre os juristas, o tema era absolutamente silenciado. Essa informação é relevante, pois demonstra claramente que em sociedades democráticas os direitos não são questões meramente técnicas, exclusivas daqueles versados nas leis. Ao contrário, são produções sociais que têm origem na luta contra as injustiças e na permanente redefinição sobre o que significa ser um cidadão merecedor de igual respeito e consideração.

A recriação do Consea $^{5}$, em 2003, permitiu um amplo diálogo entre sociedade civil e governo, além de se constituir como mais um espaço de pressão por políticas públicas e pela positivação do direito à alimentação. A Losan foi pensada e exaustivamente debatida dentro e fora do Consea. É o resultado das pressões e convergências entre sociedade civil e governo, refletindo seus acúmulos e limitações históricas.

Direitos surgem de processos de aprendizado social sobre o que significa ser um cidadão, sobre quais obrigações fundamentais devem ser garantidas de forma simétrica e recíproca entre pessoas que se compreendem como iguais. A Losan é uma importante etapa dessa marcha: é o momento em que o Estado brasileiro abre-se para um rico movimento democrático, tornando-se permeável e assumindo seus acúmulos.

\footnotetext{
${ }^{4}$ VALENTE, L. S. V. Direito humano à alimentação: desafios e conquistas. São Paulo: Cortez, 2002.
}

${ }^{5} \mathrm{Em}$ 1995, o governo Fernando Henrique extinguiu o Consea. 
Com promulgação da Losan, a garantia do direito à alimentação torna-se mais que uma reivindicação social. Transforma-se em um compromisso estatal, sendo dever do Estado efetivá-lo. As instituições e os poderes estatais, a exemplo do Executivo, Judiciário, Legislativo e Ministério Público, tornam-se responsáveis por sua implementação.

Contudo, a positivação não retira a importância da luta da sociedade civil. Os artigos presentes nesta seção comprovam isso. Eles enunciam novos desafios e demandas, (re)leituras necessárias, atualizações hermenêuticas do que foi positivado. São disputas sobre algo que permanece aberto: afirmar o direito à alimentação frente a novos contextos sociais, diante da descoberta de novas violações, pressionando o Estado e suas instituições para que atuem no sentido de lhe dar maior aplicabilidade.

A Losan não é o fim das discussões e dos aprendizados sobre o que significa o direito à alimentação adequada. O que são "práticas alimentares promotoras de saúde"? O que é "acesso regular e permanente a alimentos de qualidade"? Qual a relação entre alimentação e acesso à informação? Essas são apenas poucas perguntas de uma enormidade de questões que a legislação suscita. Ela não é o ponto de chegada, mas um marco inicial, um lugar comum para o início de uma caminhada que se almeja democrática (Losan).

A interpretação e a luta sobre o que são os direitos desenvolvem-se por meio de uma pluralidade de vozes. Nesse sentido, Tarcisio Miguel Teixeira insere-se nesse diálogo ao defender uma mudança radical na relação entre informação e agrotóxicos. De forma muito pertinente, questiona o porquê de a legislação não obrigar a rotulação de alimentos contaminados por agrotóxicos. Por que somente informar o consumidor quando o alimento é orgânico? Por que naturalizar o consumo de veneno?

Com Rosana Magalhães pode-se aprender sobre a tensão entre direito e mercado no processo de regulação dos alimentos. Ela demonstra que um reduzido número de corporações internacionais, com enorme força, apropria-se da alimentação como um bem privado. Igualmente alerta sobre a importância de preservar a alimentação como um bem público, assegurado a todos como um direito.

Pedro Affonso Duarte Hartung e Ekaterine Valente Karageorgiadis fazem um forte questionamento ao Estado e ao mercado demonstrando, com base na Losan, na jurisprudência e na legislação consumerista, que há fundamento legal para se proibir a publicidade voltada para crianças, em especial de alimentos pouco saudáveis. Oferecem, assim, fortes argumentos para uma revisão jurisprudencial, bem como das próprias políticas públicas e regulações existentes sobre o assunto.

Por fim, cabe afirmar que, se a construção de direitos é um processo democrático aberto, sempre comportando riscos de retrocesso, os artigos desta sessão certamente apontam novas fronteiras para se pensar o direito humano à alimentação adequada no Brasil. 
Rocha E. G.

\section{Referências}

ROCHA, E. G. Direito à alimentação: teoria constitucional-democrática e políticas públicas. São Paulo: LTr, 2011.

VALENTE, L. S. V. Direito humano à alimentação: desafios e conquistas. São Paulo: Cortez, 2002.

Eduardo Gonçalves Rocha - Doutor em Direito pela Universidade de Brasília. Professor da Universidade Federal de Goiás. Goiânia/GO, Brasil. E-mail: eduardofdufg@yahoo.com.br. 